\title{
New Disease Reports \\ First report of Fusarium oxysporum causing potato dry rot in Solanum tuberosum in Colombia
}

\author{
L. Garcia Bayona ${ }^{1 *}$, A. Grajales ${ }^{1}$, M.E. Cardenas $^{1}$, R. Sierra ${ }^{1}$, M.C. Cepero de Garcia ${ }^{1}$, A. Bernal ${ }^{1}$, P. Jimenez ${ }^{2}$ and S. \\ Restrepo ${ }^{1}$ \\ ${ }^{1}$ Laboratorio de Micologia y Fitopatologia LAMFU, Universidad de los Andes, Carrera 1 \#18-10, J-205, Bogota, Colombia; ${ }^{2}$ \\ Laboratorio de Fitopatologia, Universidad Militar Nueva Granada, Bogota, Colombia \\ *E-mail: leonorgb@mit.edu
}

Published: 04 Oct 2011. Keywords: intergenic ribosomal spacer, formae speciales, tuber dry rot

Fusarium oxysporum has a worldwide distribution and is responsible for vascular wilt or root rot in many plants. Strains are classified into formae speciales based on their high degree of host specificity, for which multilocus sequence typing provides a good estimate (Lievens et al., 2008). In August 2008, potato tubers (Solanum tuberosum subsp. andigena) showing symptoms of extensive dry rot were bought at a supermarket in Bogota, Colombia. They were surface sterilised and pieces of the lesion leading edge were incubated on potato dextrose agar (PDA) for one week in the dark at $27^{\circ} \mathrm{C}$. Two different isolates (single spore cultures) were recovered, which were named FoSt01 and FoSt02. Both isolates showed macroscopic and microscopic morphologies consistent with the type description for $F$. oxysporum but had distinct colony morphologies. On PDA FoSt01 produced sparse white aerial mycelium with a strong dark purple pigment diffusing into agar, visible from both sides of the petri dish. By contrast, isolate FoSt02 produced abundant light purple aerial mycelium and the underside of colonies varied from pale tan to light purple. On carnation leaf agar (Fisher et al., 1982), both isolates produced abundant single or two-celled oval (FoSt02) or kidney shaped (FoSt01) microconidia.

For each isolate, 12 sterile tubers were wounded, inoculated with agar plugs from a one-week-old PDA culture, and incubated at $25^{\circ} \mathrm{C}$ and 95 percent $\mathrm{RH}$ for 30 days in the dark. Both isolates induced moderate dry rot in all the tubers (between 0.3 and $3.5 \mathrm{~cm} 3$ rot volume) (Peters et al., 2008), but FoSt01 produced larger lesions than FoSt02 (one-way ANOVA, $\mathrm{p}<0.001)$. The pathogen was then recovered from the inoculated tubers. In comparison, no lesions were observed in tubers inoculated with sterile agar plugs or a $F$. oxysporum strain pathogenic to Passiflora ligularis. Ribosomal internal transcribed spacer (ITS) and a 650 bp section from the intergenic spacer region (IGS) were amplified by PCR using the primer combinations ITS1/ITS 4 and FIGS11/FIGS12 respectively (Kawabe et al., 2005). Sequences of both loci were identical for both isolates (GenBank Accession Nos. GU132455, GU132456). Homology searches with the IGS sequence in the nr database from GenBank and the Fusarium ID database (http://isolate.fusariumdb.org/index.php), showed that both isolates are included in the species complex 2 and are most similar (99 percent) to two non-pathogenic Fusarium oxysporum isolates, obtained from birsdsfoot trefoil (Lotus corniculatus) and Lycopersicon $s p$. rhizosphere, and to an isolate pathogenic to red clover (Trifolium pratense). The isolates induced wilt after one week in eight red clover plants that were artificially wounded in the roots and submerged in a suspension of conidia $(1 \times 104$ microconidia/ml). To the best of our knowledge, there are no previous reports on the occurrence of dry rot on tubers in Colombia caused by $F$. oxysporum. Potato dry rot is mainly a post harvest disease and could become a problem in Colombia since this country is the fourth-largest potato producer in South America.

\section{References}

Fisher NL, Burgess LW, Toussoun TA, Nelson PE, 1982. Carnation leaves as a substrate and for preserving cultures of Fusarium species. Phytopathology 72, 151-153. [doi:10.1094/Phyto-72-151]

Kawabe M, Kobayashi Y, Okada G, Yamaguchi I, Teraoka T, Arie T, 2005. Three evolutionary lineages of tomato wilt pathogen, Fusarium oxysporum f. sp. lycopersici, based on sequences of IGS, MAT1, and pgl, are each composed of isolates of a single mating type and a single or closely related vegetative compatibility group. Journal of General Plant Pathology 71, 263-272. [doi:10.1007/s10327-005-0203-6]

Lievens B, Rep M, Thomma BPHJ, 2008. Recent developments in the molecular discrimination of formae speciales of Fusarium oxysporum. Pest Management Science 64, 781-788. [doi:10.1002/ps.1564]

Peters JC, Lees AK, Cullen DW, Sullivan L, Stroud GP, Cunnington AC, 2008. Characterization of Fusarium spp. responsible for causing dry rot of potato in Great Britain. Plant Pathology 57, 262-271. [doi:10.1111 j..1365-3059.2007.01777.x ]

To cite this report: Garcia Bayona L, Grajales A, Cardenas ME, Sierra R, Cepero de Garcia MC, Bernal A, Jimenez P, Restrepo S, 2011. First report of Fusarium oxysporum causing potato dry rot in Solanum tuberosum in Colombia. New Disease Reports $24,14$. [doi:10.5197/j.2044-0588.2011.024.014] (C) 2011 The Authors 